[Fifth CONTribution from the Color Investigation Laboratory, BurEaU OF ChEMISTRY, DepartMent OF Agriculture.]

\title{
THE USE OF THYMOLSULFOPHTHALEIN AS AN INDICATOR IN ACIDIMETRIC TITRATIONS.
}

By ARtgur B. Clark aNd HERBERT A. LUBS.

Received June 26, 1918.

Thymolsulfophthalein is one of a number of indicators synthesized by W. M. Clark and H. A. Lubs ${ }^{1}$ in the course of their studies on the colorimetric determination of the hydrogen-ion concentration of biological fluids. It was found to have the property of showing brilliant color changes at two widely different hydrogen-ion concentrations. At hydrogen-ion concentrations between $\mathrm{IO}^{-1}$ and $\mathrm{IO}^{-3}$ the color changes from deep magenta to yellow, this color persisting until a hydrogen-ion concentration of $10^{-8}$ is reached when the transformation to a deep blue begins. $^{2}$ The acid working range of this indicator corresponds to that for which methyl violet and mauvein have been used, and the alkali range corresponds very closely to the region in which the color changes of phenolphthalein are observed. The unique properties of this 3-color indicator make possible many differential acidimetric and alkalimetric titrations.

A discussion of the theory of acidimetric and alkalimetric titrations is beyond the scope of this brief paper and would be unnecessary since a most comprehensive treatment may be found in a monograph on this subject by Bjerrum, and in a recent book by Prideaux, ${ }^{3}$ hence only such points will be discussed as are of especial interest in connection with the titrations herein described.

In selecting an indicator for a specific titration one must take into consideration the hydrogen-ion concentration at the end-point, and the working range 4 of possible indicators. In general, it is possible to titrate two acids (or an acid and its salt with a weak base), if the dissociation constants differ to such a degree that the stronger acid is practically completely neutralized before the alkali begins to neutralize the weaker acid,

${ }^{1}$ H. A. Lubs and W. M. Clark, J. Wash. Acad. Sci., 5, 609 (I9I5); 6, 481 (I9I6); W. M. Clark and H. A. Lubs, J. Bact., 2, I, I09, I37 (I9I7); Lubs and Acree, ThIs JOURNAL, 38, 2772 (1917).

${ }^{2}$ Expressed in terms of $P_{\mathrm{H}}$ the ranges are red to yellow from $P_{\mathrm{H}} 1.2$ to 2.8 ; yellow to blue from $P_{\mathrm{H}}$ 8.0 to 9.6.

${ }^{3}$ Bjerrum, "Die Theorie der alkalimetrischen und azidimetrischen Titrierungen," I9I4; Prideaux, "The Theory and Use of Indicators," I917.

4 The useful working range of an indicator is that range of hydrogen-ion concentration, within which the allowable variation of hydrogen-ion concentration (here taken arbitrarily at $10 \%$ ) produces a visible change in color. It is evident that the working range $b f$ an indicator may be changed by change in concentration of the indicator and will be increased by an increase (from $10 \%$ ) of the allowable variation in hydrogen-ion concentration. 
and if indicators are obtainable whose working range includes the hydrogen-ion concentrations of the end-points. Since thymolsulfophthalein has two widely separated working ranges, it is possible to titrate a strong mineral acid in the presence of one of the comparatively weak acids. The end-point of the neutralization of the strong acid, in the presence of the weak acid, lies in the acid working range of this indicator, and the neutralization of the weak acid is complete when the first change of color in the alkali range is observed.

Previous methods for differential titrations have involved the simultaneous, successive, or separate use of two indicators, but no indicator or generally employed combinations of two indicators will permit of the variety of titrations attainable by the use of thymolsulfophthalein. It will be understood that the above statements in regard to acids apply equally well to bases.

\section{The Differential Titration of Mixtures of Benzoic Acid and Hydro- chloric Acid.}

The differential titration of a mixture of an organic acid and hydrochloric acid is one for which thymolsulfophthalein is peculiatly valuable as an indicator, since many organic acids are almost entirely undissociated at a concentration of hydrogen ions at which hydrochloric acid dissociates nearly completely. Thus, if a saturated aqueous solution of benzoic acid, to which a known amount of indicator solution has been added, is used as a color standard, the hydrochloric acid content of an unknown mixture can be very accurately determined by titrating the unknown solution with approximately normal sodium hydroxide (taking care that the indicator concentration is identical with that of the standard) until the two colors are matched as closely as possible. This color in the concentration found most serviceable is a very pale orange or yellow. The titration may then be continued until the first trace of blue in the alkali range is reached, showing that all the benzoic acid has been neutralized. Since the accuracy of the titration depends entirely on the accuracy of comparison of the unknown solution with the standard, it is highly important that the same amount of indicator be used in both, that the final volumes be the same, and that they be compared in a uniform light of daylight quality. In general, the titrations reported here were made by one of us on unknown mixtures prepared by the other, in order that so far as possible the personal element of an individual worker would be avoided.

An unknown amount of benzoic acid was dissolved in $50 \%$ alcohol. Definite volumes of this solution were mixed with known amounts of hydrochloric acid and the mixture titrated.

Ten $\mathrm{cc}$. of the benzoic acid solution dissolved in $40 \mathrm{cc}$. of water was 
used as a standard. One cc. of a $0.02 \%$ aqueous solution ${ }^{1}$ of indicator was added for each $50 \mathrm{cc}$. of solution to be titrated.

TABLE I. ${ }^{2}$

Titration of Mixtures of Benzoic and Hydrochloric Acids.

\begin{tabular}{|c|c|c|c|c|c|}
\hline $\begin{array}{l}\mathrm{C}_{6} \mathrm{H}_{3} \mathrm{COOH} \\
\text { sol. Cc. } \\
\text { used. }\end{array}$ & $\begin{array}{l}0.995 \mathrm{~N} \\
\text { HCl. Cc. } \\
\text { used. }\end{array}$ & $\begin{array}{l}\text { Cc. } 1.03 \mathrm{~N} \\
\text { NaOH to } \\
\text { standard. }\end{array}$ & $\begin{array}{l}\mathrm{Cc} . \mathrm{NaOH} \\
\text { to blue. }\end{array}$ & $\begin{array}{l}\text { Cc. } \mathrm{HCl} \\
\text { found. }\end{array}$ & $\begin{array}{l}\text { G. of benzoic } \\
\text { per cc. of } \\
\text { sol. found. }\end{array}$ \\
\hline IO & 0 & . & 0.44 & . & 0.0055 \\
\hline o & 5 & . . & 4.82 & 5.0 & $\ldots$ \\
\hline IO & 5 & 4.82 & $5 \cdot 30$ & 5.0 & 0.0060 \\
\hline 25 & 5 & $4.8 \mathrm{I}$ & 5.92 & 5.0 & 0.0056 \\
\hline 50 & I & 0.95 & 3.12 & 0.99 & 0.0055 \\
\hline
\end{tabular}

\section{The Differential Titration of Mixtures of Acetic Acid and Hydro- chloric Acid.}

The titration of mixtures of hydrochloric and acetic acids is interesting in that acetic acid gives the highest hydrogen-ion concentration ${ }^{3}$ of the "weak" acids which may be conveniently titrated in the presence of strong mineral acids using thymolsulfophthalein as the indicator. In this case the method of preparing the standard differs slightly from that used in the benzoic acid titration as fairly concentrated acetic acid gives a pronounced orange color with the indicator. Since the variation in hydrogen-ion concentration of a solution of acetic acid, due to changes in the total concentration of acid, is greater than in the case of benzoic acid, we must be sure that the indicator color assumed as the end-point for the titration is produced by acetic acid alone. That is, if we have a solution containing roo times as much acetic acid as hydrochloric, and titrate to the pale orange which is produced by dilute acetic acid, the results will be in error since some of the acetic acid has been titrated as hydrochloric acid before the arbitrary standard color is reached. However, $i \mathrm{i}$ the titration is continued to the netutral point it will be immediately observed that the concentration of acetic acid is very high in comparison with the concentration of hydrochloric acid. If now the titration is repeated,

${ }_{1}$ To prepare an aqueous solution of the thymolsulfophthalein, place $0 . I \mathrm{~g}$. of the dry powder in a small weighing bottle and add 0.25 cc. $N$ NaOH (about I.I mols). Then add about one cc. of water and warm on water bath for a few minutes. The indicator dissolves and the solution can then be diluted to the desired volume. To prepare an alcoholic solution of the indicator, dissolve the dry powder in $95 \%$ alcohol.

${ }^{2}$ In the titration of weak organic acids, like benzoic or acetic, it is necessary to exclude carbon dioxide if precise results are desired. For the effect of carbon dioxide on the titration of benzoic acid see Morey, Bull. Bur. Standards, 8, 643-50 (I9I3). In these titrations an accurately calibrated $25 \mathrm{cc}$. buret, graduated according to the specifications of the U.S. Bureau of Standards, was used and the readings made with great care. An accurately calibrated narrow bore $10 \mathrm{cc}$. buret would be even more desirable, since the amount of normal alkali to titrate the organic acid present is often very small.

3 This is due to the unlimited solubility of acetic acid in water. Its dissociation constant is actually less than that of benzoic acid. 
using as a standard a solution whose content of acetic is made just equal to the amount of acetic acid found in the first titration, the results will attain remarkable accuracy. As an example, we may take titration number one in the table below. Here the concentration of acetic acid was I I times that of the hydrochloric acid. In the first titration, to an arbitrary end-point, it was found that there was present hydrochloric acid equivalent to r. $25 \mathrm{cc}$. of alkali. However, on continuing the titration to the neutral point (blue) it was found that an additional I I.oo cc. was required. The titration was then repeated, using as the standard solution of acetic acid containing the approximate equivalent of II.O cc. of alkali. In this titration $\mathrm{I} . \mathrm{OO} \mathrm{cc}$. of alkali were found equivalent to the hydrochloric acid present, the total titer being the same as in the first titration to the limit of accuracy of reading the buret. On calculating the original content of acetic and hydrochloric acids from this second titration, we find ro. $05 \mathrm{cc}$. of acetic acid and $0.96 \mathrm{cc}$. of hydrochloric acid, which is a satisfactory agreement. In titration No. 3 the ratio of acetic to hydrochloric was 28 to one. The preliminary titration indicated the presence of a large amount of acetic acid and the titration was repeated as described above. The agreement then obtained is fairly close to the theoretical.

TABLE II.

Titration of Mixtures of Acetic and Hydrochloric Acids.

I cc. of $0.02 \%$ solution of indicator was used for each $50 \mathrm{cc}$. of solution to be titrated.

\begin{tabular}{|c|c|c|c|c|c|c|}
\hline & \multicolumn{2}{|c|}{ Acid used. } & \multicolumn{2}{|c|}{ Alkali used. } & \multirow{2}{*}{\multicolumn{2}{|c|}{ Ce. acid found. }} \\
\hline & \multirow{2}{*}{$\begin{array}{l}\text { Cc. } \\
0.953 N \\
\mathrm{HCl} .\end{array}$} & \multirow{2}{*}{$\begin{array}{c}\text { Ce. } \\
1.03 N \\
\mathrm{CH}_{3} \mathrm{COOH} .\end{array}$} & \multirow{2}{*}{$\begin{array}{l}\text { Cc. } 0.92 \mathrm{~N} \\
\text { NaOH to } \\
\text { standard. }\end{array}$} & & & \\
\hline & & & & & $\mathrm{HCl}$. & $\mathrm{CH}_{8} \mathrm{COOH}$ \\
\hline \multirow[t]{2}{*}{ I $\ldots \ldots \ldots \ldots \ldots$} & I.O & 10.0 & $(\mathrm{I}, 25)$ & 12.25 & 0.96 & 10.05 \\
\hline & & & I., 0 & & & \\
\hline \multirow[t]{2}{*}{$2 \ldots \ldots \ldots \ldots \ldots$} & 10.0 & I.O & $(10.44)$ & II 45 & & \\
\hline & & & 10.36 & 11. 46 & 10.0 & 0.98 \\
\hline \multirow[t]{2}{*}{$3 \ldots \ldots \ldots \ldots$} & 1.0 & 25.0 & $(2.0)$ & 29.02 & & \\
\hline & & & 1.01 & 29.02 & 0.97 & 25.0 \\
\hline \multirow{2}{*}{$4 \ldots \ldots \ldots \ldots$} & 10.0 & 10.0 & $(10,60)$ & 21.55 & & \\
\hline & & & 10.26 & $2 \mathrm{I} \cdot 54$ & 9.90 & 10.07 \\
\hline
\end{tabular}

The Titration of Acetic Acid in the Presence of Sulfuric Acid.

The titration of mixtures of sulfuric and acetic acids was tried as recommended for hydrochloric and acetic acids but it was found that owing to the overlap of the titration curves of hydrogen sulfate and acetic acid, the titration was invariably in error by about $3 \%$, the amount of sulf uric acid found being low. However, if the amount of acetic is small in comparison to the amount of sulfuric acid, the titration may be carried out using the color of the indicator in water as the end-point instead of the color in presence of acetic acid. The method then gives an accuracy of 
$\pm 0.5 \%$, but is not recommended for mixtures in which the acetic acid concentration is much larger than the sulfuric acid concentration. A titration of an acetic-sulfuric acid mixture gave the following results, which are expressed in terms of alkali used:

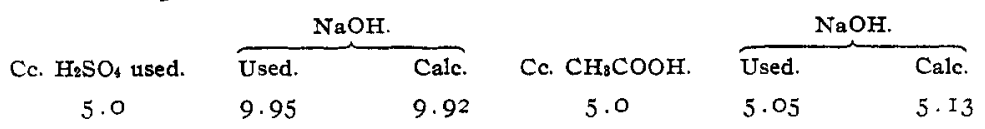

Titration of Aniline by Means of Hydrochloric Acid.

The titration of aniline hydrochloride or of aniline with standard hydrochloric acid is entirely analogous to the titration of hydrochloric and acetic acids, since we may consider aniline hydrochloride to be a weak acid analogous to acetic acid.

For the titration of aniline by means of hydrochloric acid, Julius ${ }^{1}$ suggested the use of congo red as an indicator, claiming an accuracy of $0.2 \%$. According to his procedure an aqueous solution of aniline is titrated with normal acid until the red color of the indicator has gone over to a bluish violet tinge, at which point further addition of small amounts of acid produce no appreciable change. In attempting the titration according to Julius, we could not obtain satisfactory results, being unable to judge when the acid point was reached. Even when titrating to a standard no more success was attained.

Using thymolsulfophthalein as the indicator, it was attempted to titrate to such a definite hydrogen-ion concentration that aniline hydrochloride would not be appreciably hydrolyzed, the true titer being obtained by subtracting from the titration an amount of hydrochloric acid equivalent to that necessary to bring an equal volume of water up to that of hydrogen-ion concentration. The results obtained were not in so good agreement as those given below, possibly because of the "salt effect" of aniline hydrochloride on the indicator.

In the case of entirely unknown mixtures of aniline and hydrochloric acid the system of double titration used for hydrochloric and acetic acids may be used, but if the aniline content is even approximately known, a standard may be made up from a stock solution of standard aniline hydrochloride. When a carefully measured amount of indicator solution is added, this becomes the standard for the titration. It is very important that the concentration of indicator should be carefully adjusted, so a known volume of indicator solution was used. One-half cc. of $0.1 \%$ indicator solution was added for each $25 \mathrm{cc}$. of solution. Two methods were used for the determination of aniline. In the first an excess of standard acid was added and the titration carried out as in the case of an unknown mixture, and in the second the aniline was titrated

+ J. Chem. Ind., 9, IO9 (I886). 
directly with hydrochloric acid to the color of the standard. The results are shown in the following table:

TABLE III.

Titration of Aniline by Means of Hydrochloric Acid.

The figures in this table are the results of 4 consecutive titrations.

A standard solution of aniline hydrochloride prepared containing $10.00 \mathrm{~g}$. aniline and $107.4 \mathrm{I} \mathrm{cc} . \mathrm{N} \mathrm{HCl}$ and made up to $250.0 \mathrm{cc}$.

Titration in the presence of an excess of $\mathrm{HCl}$.

$\begin{array}{cccccc}\text { Charge. } & \begin{array}{c}0.995 N \\ \text { HCl added. }\end{array} & \begin{array}{c}1.03 \mathrm{~N} \mathrm{NaOH} \\ \text { to standard. }\end{array} & \begin{array}{c}\text { NaOH } \\ \text { to blue. }\end{array} & \begin{array}{c}\text { Anilin } \\ \text { found. }\end{array} \\ 1 \ldots \ldots \ldots \ldots \ldots & \text { I.09T } & 19.97 & 7.90 & 11.42 & 1.093 \\ 2 \ldots \ldots \ldots \ldots & 1.070 & 20.30 & 8.38 & 11.14 & 1.068\end{array}$

Titration of aniline directly with standard $\mathrm{HCl}$.

\begin{tabular}{|c|c|c|}
\hline & Charge. & $\begin{array}{l}\mathrm{Cc} .0 .995 \mathrm{~N} \\
\text { HCl required. }\end{array}$ \\
\hline $1 \ldots \ldots \ldots \ldots \ldots \ldots \ldots$, & I. 108 & II. 98 \\
\hline $2, \ldots \ldots \ldots \ldots \ldots \ldots \ldots \ldots \ldots \ldots$ & I. 282 & 52.87 \\
\hline
\end{tabular}

The Titration of Aniline by Means of Sulfuric Acid.

It is possible to titrate aniline in the presence of sulfuric acid with an accuracy of $\pm 2 \%$ but the titration is not recommended since the endpoint at $\left(\mathrm{C}_{6} \mathrm{H}_{6} \mathrm{NH}_{2}\right)_{2} \mathrm{H}_{2} \mathrm{SO}_{4}$ is on the alkali end of the acid working range, and the end-point of $\left(\mathrm{C}_{6} \mathrm{H}_{5} \mathrm{NH}_{2}\right) . \mathrm{H}_{2} \mathrm{SO}_{4}$ is barely on the acid range. The titration below was carried out to the latter end-point but great care is necessary in judging the end-point and the procedure is not recommended for the determination of aniline.

I.04 g. aniline required I I.05 cc. $2.01 \mathrm{~N} \mathrm{H}_{2} \mathrm{SO}_{4}$.

$1.03 \mathrm{~g}$. aniline found.

\section{Summary.}

Thymolsulfophthalein, an indicator having two useful working ranges, can be very successfully employed in many differential acidimetric and alkalimetric titrations. To illustrate the general method of employment, a few typical titrations are given. Any acid with a dissociation equal to or weaker than acetic acid, may be differentially titrated in the presence of hydrochloric acid, provided that the weaker acid is completely neutralized when the alkaline color change of the indicator occurs.

In general, it may be said that the use of proper color screens, or better still, a colorimeter of spectrophotometer, greatly increases the accuracy of these differential titrations, but their use is not described since they are not available in most laboratories.

We are of the opinion that many other useful applications of thymolsulfophthalein as an indicator may be developed and we trust that other workers will find it of service in their various fields.

Washington, D. C. 